\title{
Ectopic corticotropin-releasing hormone syndrome caused by pancreatic neuroendocrine tumor localized by ${ }^{68} \mathrm{Ga}$-DOTATATE PET/CT
}

\author{
Guozhu Hou $^{1,2} \cdot$ Yuanyuan Jiang ${ }^{1,2} \cdot$ Wuying Cheng ${ }^{1,2}$ \\ Received: 11 September 2018 / Accepted: 25 November 2018 / Published online: 5 December 2018 \\ (C) Springer-Verlag GmbH Germany, part of Springer Nature 2018
}

A 23-year-old female patient presented with anxiety, insomnia, hirsutism, skin pigmentation, obesity, and muscle weakness for 7 months. The results of serum ACTH, low-dose dexamethasone suppression tests (DSTs), high-dose DSTs, and inferior petrosal sinus sampling implicated that the symptoms might be caused by ectopic Cushing syndrome (ECS), due to the secretion of adrenocorticotropin hormone (ACTH) or corticotropin-releasing hormone (CRH). In order to locate the ectopic origin, the patient underwent ${ }^{68} \mathrm{Ga}$-DOTATATE and ${ }^{18} \mathrm{~F}$-FDG PET/CT. ${ }^{68} \mathrm{Ga}$-DOTATATE PET/CT imaging(a-d) revealed one lesion on pancreas $(\mathrm{d}$, arrow) and multiple lesions on liver. While the pancreas showed no abnormality on ${ }^{18} \mathrm{~F}$ FDG PET/CT imaging (e-h, arrow), and the lesions on the liver were fewer and smaller than that on ${ }^{68} \mathrm{Ga}$-DOTATATE. Neuroendocrine tumors (NET, Ki67 > 15\%) were confirmed by histopathological results of biopsy on liver and pancreas. Immunohistochemical analysis was positive for $\mathrm{CRH}$ and negative for ACTH.

The clinical presentations of ectopic CRH syndrome might be similar to that of ectopic ACTH syndrome, so the differential diagnosis of these two diseases is important. Commonly, the tumors associated with ectopic CRH secretion are pheochromocytoma, medullary thyroid carcinoma, and prostate cancer [1]. Ectopic ACTH and CRH co-secreting tumor and ectopic ACTH secreting tumor detected by ${ }^{68} \mathrm{Ga}$-DOTA-peptide PET/CT were described on case reports [2,3], but ectopic

Wuying Cheng

cwypumch@126.com

1 Department of Nuclear Medicine, Peking Union Medical College Hospital Chinese Academy of Medical Sciences and Peking Union Medical College, Beijing 100730, China

2 Beijing Key Laboratory of Molecular Targeted Diagnosis and Therapy in Nuclear Medicine, Beijing 100730, China
CRH-secreting NET observed by ${ }^{68}$ Ga-DOTA-peptide PET/ $\mathrm{CT}$ has never been reported. ${ }^{18} \mathrm{~F}-\mathrm{FDG}$ is less sensitive to highgrade NET, and ${ }^{68} \mathrm{Ga}$-DOTATATE PET/CT could plays a good complementary role to identify the source of ectopic CRH secretion.
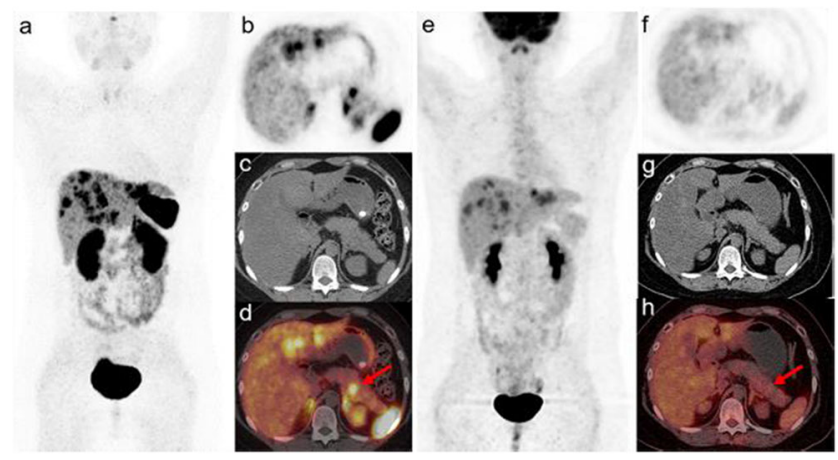

Funding This report was supported by the National Natural Sciences Foundation of China (No. 81371588, No. 81101074).

\section{References}

1. Shahani S, Nudelman RJ, Nalini R, Kim HS, Samson SL. Ectopic corticotropin-releasing hormone (CRH) syndrome from metastatic small cell carcinoma: a case report and review of the literature. Diagn Pathol. 2010;5:56. https://doi.org/10.1186/1746-1596-5-56.

2. Treglia G, Salomone E, Petrone G, Giaccari A, Rindi G, Rufini V. A rare case of ectopic adrenocorticotropic hormone syndrome caused by a metastatic neuroendocrine tumor of the pancreas detected by 68Ga-DOTANOC and 18F-FDG PET/CT. Clin Nucl Med. 2013;38: e306-8. https://doi.org/10.1097/RLU.0b013e318279ec68.

3. Papadakis GZ, Bagci U, Sadowski SM, Patronas NJ, Stratakis CA. Ectopic ACTH and CRH co-secreting tumor localized by $68 \mathrm{Ga}-$ DOTA-TATE PET/CT. Clin Nucl Med. 2015;40:576-8. https://doi. org/10.1097/rlu.0000000000000806. 